\title{
Application of Zigbee Technology in Electric Meter System of the Intelligent Community
}

\author{
Jie Huang \\ College of Mechanical and Electronic Engineering, Hezhou University, Hezhou, China, 542899 \\ huangjie0773@163.com
}

Keywords: Zigbee technology; Intelligent community; Electric meter system; GSM

\begin{abstract}
In order to be efficient and accurate statistics of the electricity consumption and electricity bill, the users can easily check the electricity consumption and electricity bill. In consideration of the actual needs of the electric meter system, an electric meter system of the intelligent community is designed by Zigbee technology. In this paper, the structure of the system, the hardware design of the electric meter node, the software design of the electric meter node and the software design of the monitoring terminal are described. The system is tested. The results show that the functions and indicators of the system meet the design requirements. It has the advantages of convenient operation and high cost performance. It has great application value.
\end{abstract}

\section{Introduction}

Along with the development of communication technology and computer network technology, the electricity consumption of electricity meters and electricity bill can be efficient, fast and accurate statistics and accounting. Users can easily check the electricity consumption and electricity bill. It is inevitable demand of social development and the construction of intelligent community $[1,2]$. The traditional electricity meter is only used to measure and count the electricity consumption of the electricity meter. It does not have the communication function. In the traditional way of meter reading, meter reading staff needs to arrive at the scene. Then it can count and calculate the electricity consumption of the electric meter [3]. It has a large amount of work. The work efficiency is low. It is also easy to make mistakes. Users can not easily check the electricity consumption of electricity meters and the electricity bill. Zigbee technology is a kind of low speed, short distance and low power consumption of wireless communication technology. It supports tree structure, star network structure and network structure. It has the advantages of flexible networking and convenient network expansion. Zigbee technology has been widely used in environmental monitoring, smart home, space exploration and building automation [4,5].

\section{System Structure}

Electricity consumption and electricity bill can be accurate, efficient and fast statistics and accounting. Users can easily check the electricity consumption and electricity bill. In this paper, the electric meter system in an intelligent community is studied and designed by using Zigbee technology. The system consists of the electric meter node, router node, coordinator node, monitor center and server. The system structure is shown in Fig. 1. Meter node, router node and coordinator node build Zigbee wireless network through Zigbee technology. It transmits data through the Zigbee wireless network. The monitoring center is connected with the coordinator and the server through the serial port $[6,7]$.

Monitoring center can statistic and calculate for electricity consumption and electricity bill through the Zigbee wireless network. It realizes the function of remote meter reading and automatic calculation of electricity bill $[8,9]$. Users can use a computer or mobile phone to log on to the server. Then it can easily check the electricity consumption and electricity bill. 


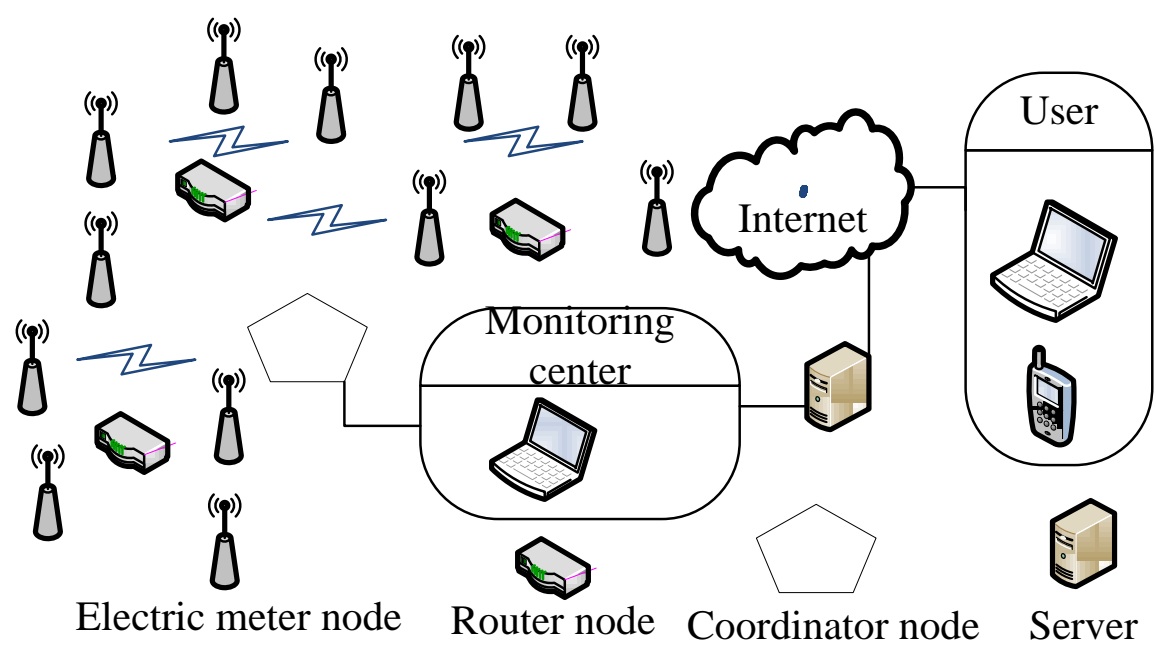

Figure 1. System structure

\section{System Design}

Node Hardware Design of Electric Meter. The hardware circuit of the electric meter node uses CC2530 chip. The main modules include GSM communication module, electric energy consumption metering module, relay control module and display module. The GSM communication module uses TC35i chip. Electric energy consumption metering module uses BL6503 chip. Display module uses OLED display. The function of the electric energy consumption measurement module is to measure and count the electricity consumption of the electric meter $[10,11]$. The hardware circuit of the electric meter node is shown in Fig. 2.

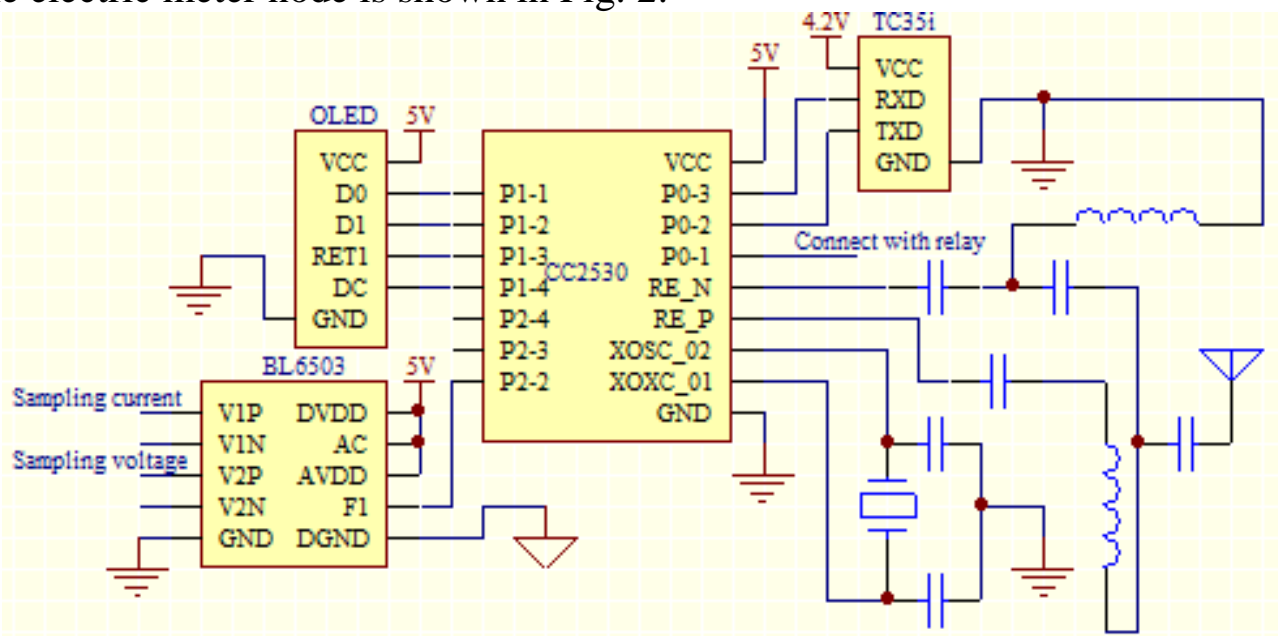

Figure 2. Electric meter node hardware circuit schematic

Function of the System. The main functions of the system are as follows.

The electric meter node has the function of wireless communication. Meter node, router node and coordinator node build the network through Zigbee technology. It can communicate with the monitoring center through Zigbee wireless network. It can also communicate with the administrator's mobile phone through the GSM network.

The system has the function of remote electricity meter reading and electricity bill calculation. Monitoring center can count and calculate the electricity consumption of electricity meters and electricity bill and other information through the Zigbee wireless network. It realizes the function of remote electric meter reading and automatic calculation of electricity bill.

The system has the function of remote control of electric meter. The monitoring center can control the power supply of the electric meter node through the Zigbee wireless network. It can also cut off the power of the electric meter node through the Zigbee wireless network. If the user does 
not pay the electricity bill, the monitoring center can cut off the power supply of the user through the Zigbee wireless network. Administrators can also control the electricity meter by phone.

The system has the function of inquiring the electricity consumption and inquiring the electricity bill. The information of electricity consumption and electricity bill is transmitted to the server to save. Users can use a computer or mobile phone to log on to the server. Then it can easily check the electricity consumption and electricity bill.

When the Zigbee wireless network failure, managers can use the phone to control the electricity meter through the GSM network.

Program Design Flow Chart of the Electricity Meter Node. Electricity consumption of the electric meter is measured and counted by the meter node. When the electricity meter node successfully joined the Zigbee wireless network, the electric meter node communicates with the monitoring center through the Zigbee wireless network and transmits the data. Managers can also use the phone to communicate with the electricity meter node. The program design flow chart of the electricity meter node is shown in Fig. 3.

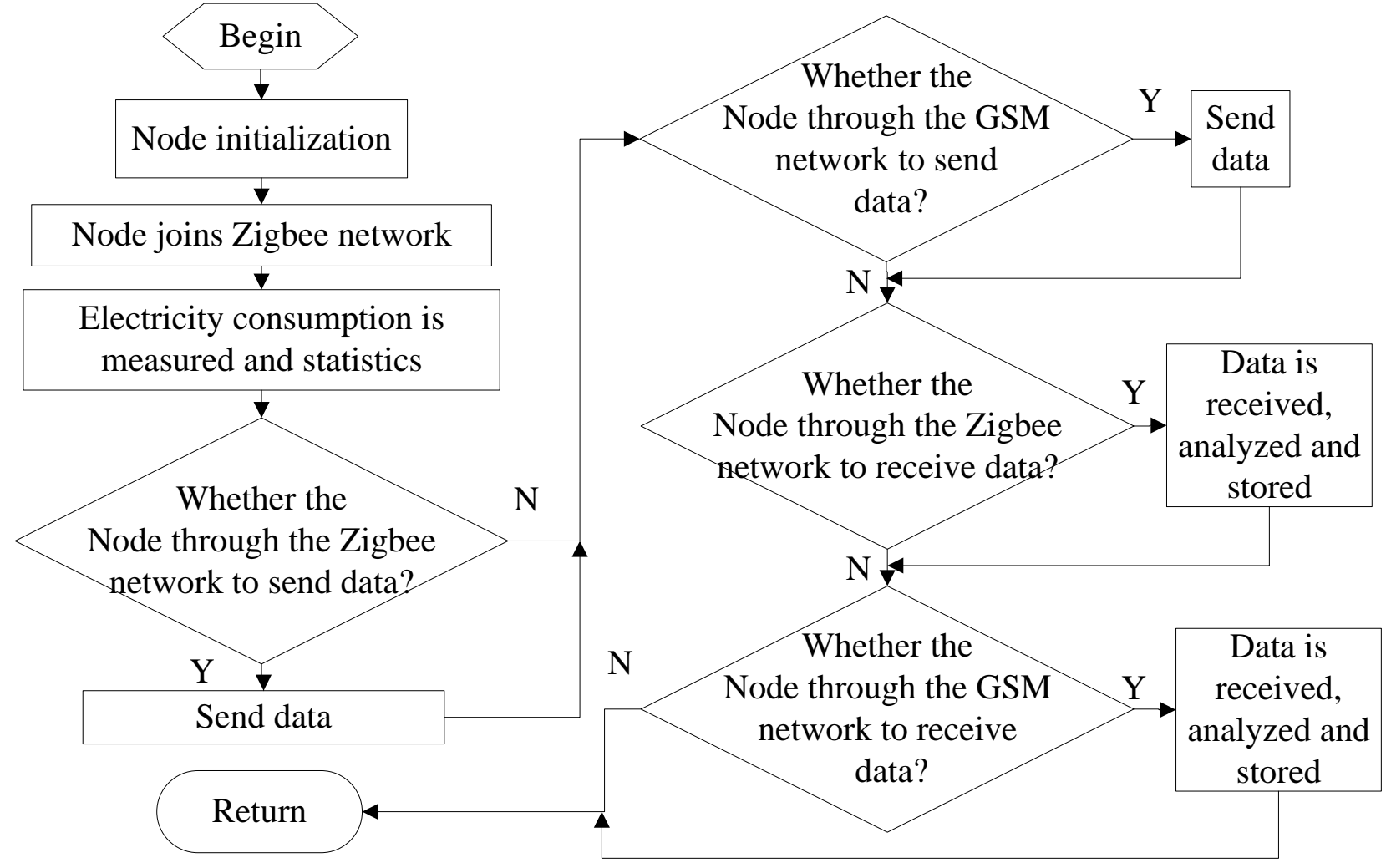

Figure 3. Program design flow chart of the electricity meter node

Program Design Flow Chart of the Monitoring Center. Monitoring center statistics and store electricity consumption of each electricity meter node. Electricity bill is also calculated and stored by the monitoring center. Electricity consumption and electricity bill are transmitted to the server through the serial port. The monitoring center can communicate and transfer data with each electricity meter node through the Zigbee wireless network or GSM network. It can also remotely manage and control the node of each electric meter through the Zigbee wireless network or GSM network. The flow chart of the program design of the monitoring terminal is shown in Fig. 4. 


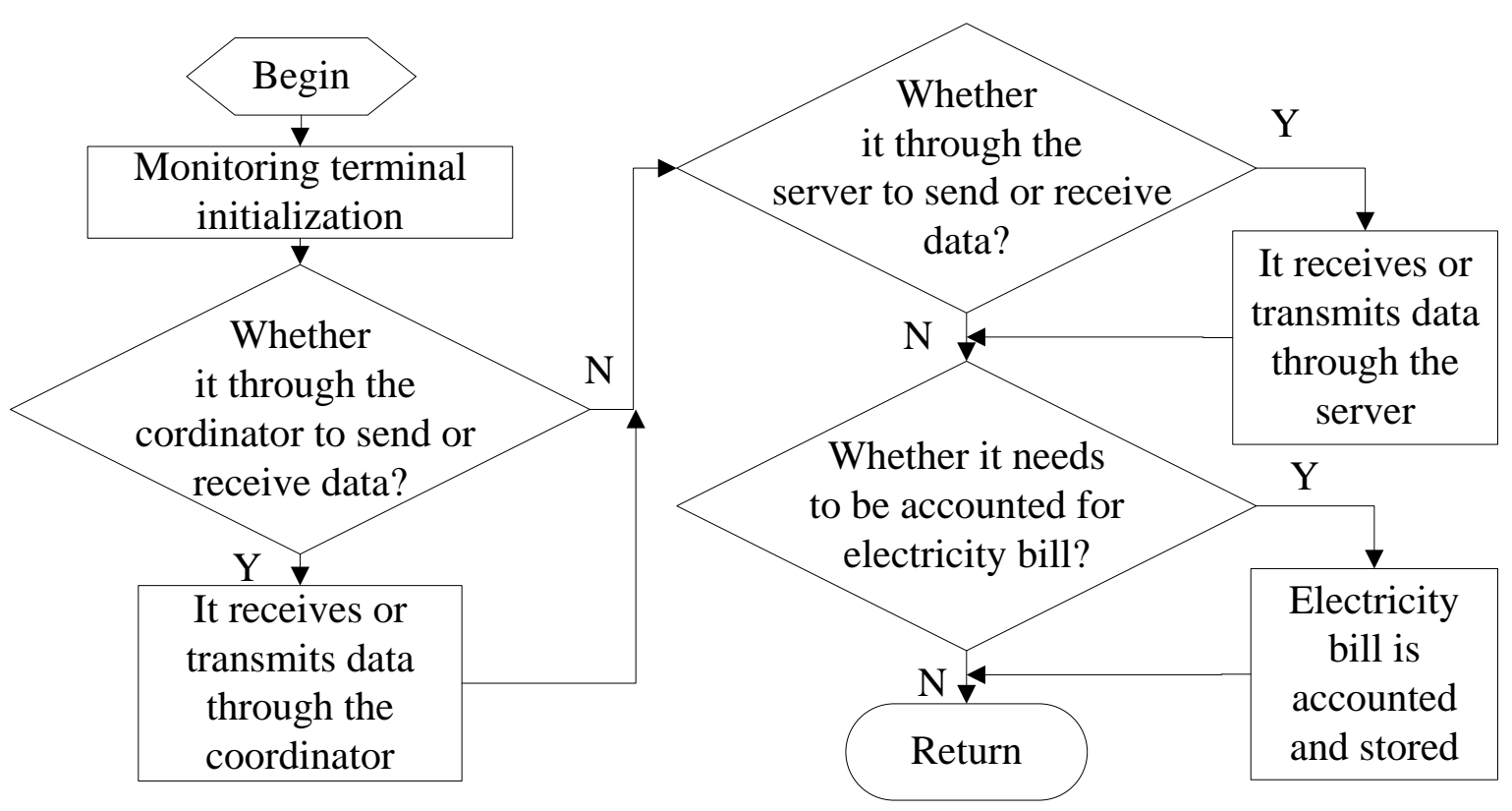

Figure 4. Program design flow chart of the monitoring terminal

\section{System Test}

In order to verify the function and feasibility of the system, the system is installed in a community. The function and feasibility of the system are tested. Electric meter nodes, router nodes and coordinator nodes are installed in different locations in the community. The test data of the system are shown in Table 1.

Table 1 System test data

\begin{tabular}{cccc}
\hline & Test item & $\begin{array}{c}\text { Test quantity of electric } \\
\text { meter node }\end{array}$ & $\begin{array}{c}\text { Success rate of } \\
\text { test items }\end{array}$ \\
\hline & $\begin{array}{c}\text { Statistical electricity } \\
\text { consumption } \\
\text { Calculation electricity } \\
\text { bill }\end{array}$ & 12 & $100 \%$ \\
Function test of \\
monitoring center & $\begin{array}{c}\text { Control test of electric } \\
\text { meter node } \\
\text { Query electricity } \\
\text { consumption }\end{array}$ & 12 & $100 \%$ \\
Query electricity bill & 12 & $100 \%$ \\
\hline
\end{tabular}

The test data show that the system can accurately statistics and calculate the electricity consumption and electricity bill. The monitoring center can control the power supply of the electric meter node through the Zigbee wireless network. It can also cut off the power of the electric meter node through the Zigbee wireless network. Users can use a computer or mobile phone to log on to the server. Then it can easily check the electricity consumption and electricity bill. The function and performance index of the system meet the design requirements of the system.

\section{Summary}

In this paper, an electric meter system of the intelligent community is designed by Zigbee technology. It consists of the electric meter node, router node, coordinator nod, monitor center and server. The electric meter node is designed by using Zigbee technology. Compared with the traditional electric meter, the meter node can not only measure and statistics the electricity 
consumption of the electric meter. It also has the function of wireless communication. The electric meter node can use Zigbee technology to network, communicate and transfer data with other nodes. It can also communicate with the administrator's mobile phone through the GSM network. Monitoring center can count and calculate the electricity consumption of electricity meters and electricity bill and other information through the Zigbee wireless network. It realizes the function of remote electric meter reading and automatic calculation of electricity bill. Users can easily check the electricity consumption and electricity meter through the server. The system has the advantages of convenient operation and good stability. It has broad application prospects.

\section{Acknowledgement}

This work was financially supported by the National Natural Science Foundation of China (Grant No.6154055), the Doctor's scientific research foundation of Hezhou University (No.HZUBS201506).

\section{References}

[1] X. Zhou, X.D. Zhu and X.B. Yu: Process Automation Instrumentation, Vol. 34 (2013) No.3, p.31. (In Chinese)

[2] J.H. Fu: Computer Knowledge and Technology, Vol. 12 (2016) No.12, p.62. (In Chinese)

[3] J.J. Shi, J. Zhong and P. Yi: Computer Engineering and Design, Vol. 32 (2011) No.3, p.875. (In Chinese)

[4] X.Q. Wang, Y.J. Ou and N.L. Huang: Design and Implementation of ZigBee Wireless Sensor Network (Chemical Industry Press, Chinese 2012), p.65. (In Chinese)

[5] Y.X. Wang and J.P. Niu: Process Automation Instrumentation, Vol. 32 (2011) No.3, p.4. (In Chinese)

[6] Y.F. Wang and S.W. Ma: Measurement \& Control Technology, Vol. 32 (2013) No.1, p.14. (In Chinese)

[7] L.M. Sun, J.Z. Li, Y. Chen and H.S. Zhu: Wireless Sensor Network (Tsinghua University Press, Chinese 2005), p.109. (In Chinese)

[8] T.F. Zhao, L.B. Chen, L. Yuan and X.Q. Hu: Computer Measurement \& Control, Vol. 24 (2016) No.9, p.298. (In Chinese)

[9] H.B. Yu, W. Liang and P. Zeng: Intelligent Wireless Sensor Network System (Science Press, Chinese 2013), P.36. (In Chinese)

[10]Z.M. Li, W.W. Liu and J.H. Wang: Measurement \& Control Technology, Vol. 31 (2012) No.6, p.50. (In Chinese)

[11]Y.G. Wang and Z. Wang: Wireless Sensor Networks (Publishing House of Electronics Industry, Chinese 2012), p.58. (In Chinese) 